\title{
Associativismo operário, educação e autonomia na formação da classe trabalhadora em São Paulo (1889-1930)
}

\author{
Ana Luiza Jesus da Costa ${ }^{1}$
}

\section{Resumo}

0 presente artigo traz parte de uma pesquisa mais ampla sobre as visões de educação e as formas pelas quais as classes trabalhadoras de São Paulo promoveram, entre 1889 e 1930, sua própria educação. Debruçamo-nos sobre uma série documental - os estatutos de associações de trabalhadores presentes no fundo do Primeiro Registro de Imóveis da Comarca da Capital (1883-1941), guardados pelo Arquivo do Estado de São Paulo. Cotejados com documentação diversa, como a imprensa operária e resoluções dos primeiros Congressos Operários brasileiros, os estatutos constituíram-se, ao mesmo tempo, em fonte e objeto de pesquisa. A análise das fontes foi feita em diálogo com referenciais da história social inglesa e da historiografia sobre a formação da classe trabalhadora e o associativismo no Brasil. Verificamos a presença da educação na arquitetura jurídica dessas entidades. Foi possível aferir a relevância e as finalidades da educação para essas associações e analisar tanto os tipos de ações educativas formais por elas desenvolvidas quanto a educação que acontecia no bojo da cultura associativa. Concluímos que a educação foi parte fundamental do processo de formação da classe trabalhadora, não exatamente como predominância de uma educação escolarizada, mas sim de uma experiência educativa relativamente autônoma e horizontal, quando tomamos como referência o Estado e a forma escolar hegemônica - o que estamos chamando de educar-se das classes trabalhadoras.

\section{Palavras-chave}

Associativismo - Classe trabalhadora - Educação - Experiência.

1- Universidade de São Paulo, São Paulo, SP, Brasil.

Contato: anajcosta@usp.br

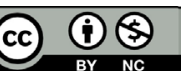

DOI: http://dx.doi.org/10.1590/S1678-4634201844179976

This content is licensed under a Creative Commons attribution-type BY-NC. 


\section{Workers' associativism, education and autonomy in the making of the working class in São Paulo (1889-1930)}

\section{Abstract}

In this article I present a slice of a broader study about the visions and practices of selfeducation by the working classes in São Paulo, between 1889 and 1930. I took a deep look at a series of documents - the bylaws of workers' associations - found in the First Real Estate Registry of the Capital's County (1883-1941), stored by the São Paulo State Archives. Compared with other documentation such as the workers' press, and resolutions of the first Workers Congresses in Brazil, the bylaws were simultaneously source and object of the research. The analysis of the sources was made in dialogue with references of the English social history and the historiography on the making of the working class and associativism in Brazil. I found that education is embedded in the very juridical framework of the workers associations. It was possible to assess the importance and goals of education for those associations. I analyzed the types of formal educational actions carried out by the associations, and the informal educational processes that developed within the associative culture. I concluded that education was a fundamental component in the making of the working class. However, the predominant form of education was not a schooled one. It was a relatively autonomous and non-hierarchical educational experience, if compared to the State and the hegemonic schooling forms. I have chosen to call this autonomous and horizontal experience as "the self-education of the working classes".

\section{Keywords}

Associativism - Working class - Education - Experience.

0 que faz da classe operária exatamente o que ela é em cada espaço e tempo histórico e como se tecem os fios de continuidade entre experiências, culturas e modos de ser da classe de trabalhadores ao longo do tempo e do espaço? A questão está longe de ser inédita, ainda que devamos sempre recolocá-la em sua historicidade. Bastaria revisitarmos a formulação feita por E. P. Thompson, cuja Formação da classe operária inglesa é uma resposta em três volumes a indicar que classe operária não é uma estrutura, ou uma categoria, mas algo que ocorre efetivamente nas relações humanas e cuja ocorrência pode ser demonstrada (THOMPSON, 2004, p. 10). Cornelius Castoriadis recolocou o problema em A experiência do movimento operário (1985). 0 que é a classe operária, o movimento operário e sua história? 0 que há séculos se faz como classe operária e movimento operário? Em suas palavras: "Qual é a relação entre os ludditas, os canutos, os operários de Poznan 
em 1956, a forma da greve geral, a instituição sindical, a Federação Anarquista Ibérica, os wobblies, Marx, Bakunin, as greves selvagens?" (CASTORIADIS, 1985, p. 46-47).

Retomamos essas perguntas como fundamentos de nosso problema de pesquisa no campo educacional. Qual o lugar da educação na formação da classe trabalhadora? Defendemos que os trabalhadores se educam como classe e que a educação é um elemento importante da referida continuidade. 0 presente artigo tem como objetivo trazer a público parte dos primeiros resultados de uma pesquisa de escopo mais amplo, na qual procuramos conhecer e compreender as formas pelas quais as classes trabalhadoras paulistas promoveram, entre 1889 e 1930, sua própria educação e construíram visões/concepções próprias sobre educação, ainda que essas não tenham conquistado hegemonia, ou sequer tenham sido sistematizadas, registradas e divulgadas pelos meios convencionais.

Quando Hall e Pinheiro $(1979,1981)$ afirmam que fazer a história da classe operária e trabalhadora não é fazer apenas uma história sindical, ou das ideologias operárias, ou das lideranças do operariado, podemos adotar o mesmo princípio para a produção da história da educação da classe trabalhadora. Esta não seria, então, exclusivamente uma história das ideias pedagógicas anarquistas, ou de outras pedagogias socialistas; nem mesmo apenas uma história das escolas criadas pelos trabalhadores. Nossa atenção voltase para a história de como os trabalhadores fizeram sua educação e de como se fizeram por meio dela.

A pesquisa abarca o período entre 1889 e 1930, justificado tanto do ponto de vista da revisão bibliográfica sobre a temática da formação da classe trabalhadora em São Paulo quanto do ponto de vista das principais séries documentais com que trabalhamos. Naquele momento, disseminaram-se as entidades das classes trabalhadoras paulistas, bem como a imprensa dos trabalhadores na cidade. Os estatutos de associações de trabalhadores por nós localizados têm suas datas mais recuadas na última década do século XIX. Tempo de desencadeamento do maior dinamismo da capital paulista em função da mudança do eixo econômico do café para o oeste paulista e do eixo político com a proclamação da República, momento marcado pelo avanço da urbanização, industrialização e pelo forte impacto da imigração para a cidade. Paramos na entrada dos anos 1930 em função da delimitação cronológica da história da formação da classe trabalhadora no Brasil, tomada de empréstimo de Ângela Castro Gomes (2005). Situamo-nos no primeiro momento dessa formação, em que "a fala estava com os trabalhadores" e estes tinham relativa autonomia diante do Estado. Para Gomes (2005), o segundo momento na história do direito do trabalho tem o Estado, a partir do Ministério do Trabalho, como lugar de fala dominante.

\section{Os estatutos de associações de trabalhadores como fontes para a história da educação}

Partimos dos sujeitos; não partimos das ideias pedagógicas anarquistas ou socialistas, nem das escolas em si promovidas por trabalhadores, militantes do movimento operário. Desejamos pensar como esses sujeitos chegaram a formular tais ideias, propor e implementar tais escolas. 
Procuramos os sujeitos em seus espaços de vivência coletiva. As associações de trabalhadores têm se mostrado terreno fértil para observação das ações educacionais da classe em formação. Ao lado da imprensa operária, o associativismo tem sido o objeto central de nossas pesquisas.

Mac Cord e Batalha (2014) remetem a história do associativismo ao Iluminismo europeu, momento de defesa da vida pública, luta por participação social mais ampla, desejo de ampliação da vida política. As diversas associações que então passaram a existir "foram idealizadas para reunir pessoas atuantes e com interesses comuns, focadas na busca de uma ideia de civilização e progresso [e fortaleceram a emergente sociedade civil]" (MAC CORD; BATALHA, 2014, p. 11). Esse processo tocará tanto as elites proprietárias e letradas como as classes trabalhadoras, que perceberam o associativismo como meio para articular suas demandas e fortalecer suas estratégias de proteção e organização.

Partindo dessas raízes, os autores realizam um breve balanço do estado atual em que se encontram os estudos sobre o associativismo. Marco da renovação em sua abordagem, a historiografia que tratava o mutualismo como infância ou pré-história da classe trabalhadora, vigente até a década de 1980, cedeu espaço à concepção processual de formação da classe na qual as associações mutualistas participam. 0 trabalho de Tânia Regina de Luca, publicado em 1990, acompanhado, anos mais tarde, pelo projeto editorial de Carlos Batalha nos Cadernos AEL, sobre "Sociedades operárias e mutualismo" foram pioneiros nesse sentido. Recentemente, vários estudos sobre o associativismo entre diferentes categorias de trabalhadores têm sido trazidos à luz, por vezes congregados em publicações como o dossiê de Mundos do trabalho, em 2010, ou no próprio Organizar e proteger trabalhadores, associações e Mutualismo no Brasil, organizados por Mac Cord e Batalha (2014).

Ao nos inserirmos no debate, nosso objetivo foi analisar, do ponto de vista educacional, tanto as associações de auxílio mútuo como as associações de resistência que conviveram no período delimitado. Uma das polêmicas centrais na história do associativismo entre trabalhadores, motivadora de debates que orientaram a renovação da historiografia sobre o tema nos anos 1980 e 1990, com repercussão até os dias de hoje, diz respeito à relação existente entre mutualismo e sindicalismo. 0 primeiro congregava sociedades que, mediante contribuições mensais, prestavam serviços previdenciários como tratamento médico, auxílio aos doentes, inválidos e viúvas, ou seja, resguardavam os sócios quando se encontrassem sem condições de trabalhar. 0 segundo caracteriza as sociedades que se organizavam com intuito de defender os interesses das categorias de trabalhadores e unir a classe operária em oposição aos patrões.

Apoiamo-nos na tese proposta por De Luca, hoje amplamente aceita, de que o mutualismo não deu origem ao sindicalismo nem se confunde com ele. Segundo a autora, as associações de socorro mútuo não eram exclusivamente operárias:

Nelas poderiam ser encontrados membros de diversas camadas sociais, assim como os mais diversos tipos de profissionais [...]. Muitas não se organizavam em torno de setores de produção, e sim por etnias, credos religiosos ou bairros. Algumas impunham restrições de ordem política, moral e religiosa ao ingresso do associado. Diversas entre elas, apesar de servirem aos trabalhadores, eram entidades dirigidas pelos patrões, que exigiam participação compulsória de todos os empregados. (DE LUCA, 1990, p. 10). 
Entretanto, se mutualismo e sindicalismo não se confundem como fenômenos, no âmbito pontual da existência das associações, podemos encontrar aquelas que se situam em uma tênue fronteira entre auxílio mútuo e resistência. Ainda que, de acordo com as deliberações dos Congressos Operários de 1906, 1913 e 1918, as associações de resistência não devessem manter atividades beneficentes, os estatutos das entidades defendiam a solidariedade e ajuda mútua aos sócios necessitados. Por outro lado, um conjunto de entidades de auxílio mútuo anuncia como objetivo intervir pelos direitos dos sócios diante de autoridades e já desenha um caráter classista ao circunscrever o voto ou reservar cargos na diretoria para trabalhadores. A Associação Beneficente Operária $1^{\circ}$ de Maio Vila Galvão afirma em seus estatutos que tinha como fim principal o socorro mútuo. Enquanto seu $19^{\circ}$ artigo determina que "Da diretoria deverão fazer parte, pelo menos metade e mais um dos sócios, cujos esses sócios [sic] sejam tirados do meio operário" (ABOPMVG, 1917, p. 8). Esse é o mesmo caso da Associação Mútua dos Carteiros de São Paulo (AMCSP), em que "só poderão ser eleitos e votar os carteiros, serventes e estafetas" (AMCSP, 1920, p. 2).

Ambas as formas de associativismo obreiro davam relevância à educação, e nos interessa perceber os pontos de contato e as diferenças entre suas visões de educação e ações educativas. De Luca (1990) destaca os aspectos educacionais das associações mutualistas, quantificando, no universo de 318 associações identificadas por sua pesquisa, os percentuais: daquelas que se propunham a ministrar aulas, conferências e palestras aos sócios e seus filhos (26\%); das que organizavam bibliotecas e gabinetes de leitura (18,3\%); das que proporcionavam festas, bailes, jogos, piqueniques e demais "divertimentos honestos" (16, 3\%); e, por fim, das que pretendiam editar jornais e revistas (3,7\%).

Para acessar o universo das mutuais, a autora utilizou como fontes principais os Anuários Estatísticos de São Paulo e os Diários Oficiais do Estado de São Paulo. E acessoriamente contou com o Boletim do Departamento de Estatística do Estado de São Paulo e o Boletim do Departamento Estadual do Trabalho. Grande parte da documentação sobre essas entidades foi constituída por força de determinações legislativas. É o caso, particularmente, de seus estatutos, principal série documental do presente artigo. A legislação que regulava as associações mutualistas surgiu em 1860: Lei 1.083 de 22/08/1860, regulamentada pelo Decreto 2.711, de 19/12/1860. Inaugurava-se a prática de controle do Estado sobre essa forma de associativismo. Pelas regras de 1860, as associações dependiam da permissão do Imperador e dos Presidentes de Província para funcionar:

Os estatutos deveriam ser enviados à autoridade competente, especificando o nome da entidade, sua sede, seus fins, a duração prevista, o valor da contribuição mensal, a forma como se pretendia empregar os fundos sociais, os serviços prestados, as atribuições dos administradores e da assembleia geral, o modo de administração, as condições para nomeação e elegibilidade dos membros e, finalmente, os critérios para admissão e eliminação de sócios, bem como o número destes. (DE LUCA, 1990, p. 14).

Essa legislação foi revista em 1882, com a abolição da necessidade de aprovação do governo para constituição de entidades literárias, científıcas, políticas ou de socorros mútuos. Anos depois, surge novo decreto, segundo De Luca, possivelmente vinculado ao 
crescimento e importância do associativismo, função da expansão urbana, da ampliação do mercado de trabalho e do recrudescimento da exploração dos trabalhadores com baixos salários e alto custo de vida. Trata-se do Decreto n. 173 de 10/09/1893, ao qual fazem referência os estatutos por nós analisados. Esse Decreto "abriu a possibilidade das sociedades de auxílio adquirirem personalidade jurídica mediante o registro de seus estatutos e a publicação de, pelo menos, parte deles no Diário Oficial do Estado" (DE LUCA, 1990, p. 16).

0 fundo do Primeiro Registro de Imóveis da Comarca da Capital (1883-1941), presente no Arquivo do Estado de São Paulo, guarda os estatutos de uma série de associações, cujo registro foi motivado pelo decreto 173 de 1893. Elas vão desde empresariais até associações diversas da sociedade civil, entre as quais as sociedades beneficentes, de auxílios mútuos, centros, ligas, grêmios, uniões e sindicatos. Trabalhamos com um total de 48 entidades. A mais antiga, criada em 1859, Sociedade Artística Beneficente, teve seus estatutos publicados em Diário Oficial no ano de 1901. A mais recente é o Centro dos Empregados no Comércio e na Indústria, inaugurado em 1920. A maior parte das associações de resistência presentes na série foi fundada entre 1917 e 1919. Distinguimos, nesse universo, 28 associações mutualistas e vinte associações de resistência. A seguir, podemos observar um panorama geral das entidades que aparecem referidas ao longo do texto.

Tabela 1 - Conjunto das associações de trabalhadores pesquisadas, referidas no texto

\begin{tabular}{|c|c|c|c|c|}
\hline Nome & Ano Fundação & $\begin{array}{l}\text { Ano Publicação dos } \\
\text { Estatutos }\end{array}$ & $\begin{array}{l}\text { Tipo (admissão de } \\
\text { sócios) }\end{array}$ & $\begin{array}{l}\text { Caráter (mutual/ } \\
\text { sindical) }\end{array}$ \\
\hline $\begin{array}{c}\text { Associação Auxiliadora dos Carpinteiros, Pedreiros } \\
\text { e mais Classes }\end{array}$ & & 1903/Junho & Profissional & Mutualista \\
\hline $\begin{array}{l}\text { Associação Beneficente Operária } 1^{\circ} \text { de Maio da } \\
\text { Vila Galvão }\end{array}$ & 1917 & 1917 & Bairro & Mutualista \\
\hline Associação Mútua dos Carteiros de São Paulo & 1910 & 1920 & Profissional & Mutualista \\
\hline $\begin{array}{c}\text { Associação dos Operários em Fábricas de Tecidos } \\
\text { da Mooca }\end{array}$ & 1918 & 1918 & Profissional/Bairro & Resistência \\
\hline Centro dos Empregados no Comércio e na Indústria & 1920 & 1920 & Profissional & Mutualista \\
\hline Centro Operário de São Bernardo & 1919 & 1919 & Bairro & Resistência \\
\hline Grêmio dos Alfaiates & 1904 & 1904 & Profissional & Mutualista \\
\hline Liga dos Trabalhadores da Light & 1919 & 1919 & Profissional & Resistência \\
\hline Liga Operária do Ypiranga & 1919 & 1919 & Bairro & Mutualista \\
\hline Sociedade Artística Beneficente & 1859 & 1901 & Aberta & Mutualista \\
\hline $\begin{array}{l}\text { Sociedade União Beneficente dos Ensacadores de } \\
\text { Café e Cereais }\end{array}$ & 1912 & 1912 & Profissional & Resistência \\
\hline União dos Chapeleiros & 1913 & 1917 & Profissional & Resistência \\
\hline União dos Trabalhadores Gráficos & - & 1919 & Profissional & Resistência \\
\hline
\end{tabular}

Fonte: Estatutos de associações de trabalhadores constantes no fundo do Primeiro Registro de Imóveis da Comarca da Capital (1883-1941) - APESP. 
Adotamos, para composição da tabela, a classificação proposta por De Luca (1990) dos tipos de associação a partir de sua base de admissão dos sócios: ${ }^{2}$ abertas, profissionais, por bairro, de empresas. Destacamos também o caráter mutualista ou de resistência predominante em cada entidade, diferença marcante para pensarmos seus projetos educacionais. Cabe notar, finalmente, que, embora suas datas de fundação variem entre 1859 e 1920, os anos de publicação de seus estatutos, sem prejuízo de reformas subsequentes, são todos posteriores a 1893, ano do decreto já citado que regula as associações da sociedade civil.

Como já foi afırmado anteriormente, este artigo se debruça sobre uma série documental específica - os estatutos das associações de trabalhadores. Procuramos demonstrar e discutir suas potencialidades e limites como fonte de pesquisa para a história da educação das classes trabalhadoras. Um olhar sobre a historiografia do movimento operário, ou mesmo da educação da classe trabalhadora no período aqui estudado, identifica a tradição que privilegia, sobretudo os trabalhadores anarquistas com ênfase nas questões doutrinárias e de projetos, bem como as ações das lideranças. Nessa historiografia, a imprensa operária é fonte privilegiada. Defendemos que a observação das experiências dos trabalhadores em formas organizativas diversas, tais como associações mutualistas e de resistência, tem a contribuir para a história da educação e da formação da classe trabalhadora, o que matiza a versão ainda corrente segundo a qual imigrantes politizados aportaram no Brasil, no início do século XX, trazendo para cá as ideologias operárias que educaram e organizaram a classe. Essa seria uma história, mas não a única história da formação da classe trabalhadora em São Paulo.

Certamente o mito do imigrante, sobretudo o italiano, como construtor de São Paulo não foi uma invenção apenas da imprensa operária, a qual segue sendo fonte da qual não se pode prescindir para discutir os mundos do trabalho, seja na esfera da produção ou de sua reprodução. Santos (2008), em tese de título sugestivo, defende que Nem tudo era italiano. Apresenta a participação de trabalhadores e populações pobres nacionais do início do século XX na construção da cidade. Apreende-os, porém, marginalmente, em fotografias que, ao pretenderem retratar o progresso da cidade, captaram no fundo da cena, fora do foco, esses sujeitos. Por outro lado, o autor demonstra o discurso veiculado na grande imprensa e em publicações oficiais como Anuários Estatísticos da cidade, que exaltavam a modernização de São Paulo e a contribuição da massa de trabalhadores imigrantes neste empreendimento. Segundo o Anuário Estatístico da Seção Demográfica de 1911, "Mesmo o progresso de São Paulo é evidente devido à influência do elemento estrangeiro, que concorre com seu espírito adiantado para a multiplicação de nossa população" (apud SANTOS, 2008, p. 31).

Apesar do longo silenciamento a que foram submetidos o negro e o trabalhador pobre nacional no pós-abolição, as questões étnico-raciais e de nacionalidades eram então motivo de tensão no seio da classe trabalhadora. Não à toa, vários estatutos das associações obreiras, particularmente as de resistência, cuja pretensão era promover a unidade da classe, enfatizavam que a organização não fazia distinção de raça, nacionalidade,

2- De Luca ainda traz à cena as associações de tipo étnico-racial. Não as incluímos aqui, pois elas têm lugar de reflexão específico no escopo mais amplo de nossa pesquisa. 
crenças; e, em menos casos, afırmava-se que não havia distinção de sexo na admissão dos sócios. Por outro lado, encontramos o determinismo presente em algumas publicações da imprensa operária que atribuíam à diversidade racial dificuldades e até mesmo fracassos na organização da classe. Giovanni Scala, militante socialista, em artigo para o jornal Avanti!, em 1914, assim lamentava:

O que mais impressiona os socialistas que chegam aqui em São Paulo, provenientes do exterior, é a falta de organização operária. [...] Em São Paulo tentou-se várias vezes atrair a massa operária para órbita da organização de classe, mas só perdeu-se tempo e palavras. 0 proletariado não dava sinais de vida. [...] Aqui faltando uma classe proletária nacional, característica do ambiente e do período histórico da produção, foi-se formando, ao invés dessa, uma classe acolhedora de elementos disparatados, de raça e de condição social, que vão do japonês ao homem de cor... (apud HALL; PINHEIRO, 1979, p. 224).

Da mesma forma, Astrogildo Pereira, militante anarquista que se tornou, mais tarde, fundador do Partido Comunista, no artigo "Nada de Precipitação", publicado em A Plebe, 1921, faz seu "exame rigoroso das causas determinantes das sucessivas crises por que tem passado a organização” (PEREIRA, 1921, p. 1). Para tanto, toma como parâmetro o movimento operário europeu, considerado mais adiantado, inclusive porque parte da história de povos "mais civilizados". Não se trata de cobrarmos anacronicamente que os trabalhadores vissem a história e a sociedade sem as lentes do etnocentrismo e do racismo hegemônicos nas primeiras décadas do século XX. Trata-se de pensar os conflitos existentes entre a classe trabalhadora no processo de sua formação e quanto o pensamento racista/etnocêntrico - e não a diversidade étnico-racial - pode ter representado uma limitação nesse processo. Para Astrogildo, um dos principais fatores das "sucessivas crises” era o ambiente:

Já se vê que é esta uma causa geral e inevitável - mas que pode e deve ser atenuada e superada. E, desde logo, o "ambiente" brasileiro aparece aos olhos do menos perspicaz observador como um ambiente mais desfavorável que favorável ao desenvolvimento da organização obreira. Somos um país sem tradições de luta proletariana [sic]. Nossa população operária é essa mescla de raças que se sabe. 0 analfabetismo, a ignorância integral das massas, mantém-nas longe do contato das correntes contemporâneas de reivindicação social. [...] Os operários do Brasil não formam um bloco homogêneo do ponto de vista racial: país de imigração, de raças e sub-raças diversas aqui se mesclam, desordenadamente (apud HALL; PINHEIRO, 1979, p. 251).

É importante observar que, ao lado do problema da heterogeneidade e das "mesclas desordenadas" entre "raças e sub-raças", estava posto quase como consequência "o analfabetismo e a ignorância integral das massas”. Três condições independentes heterogeneidade étnico-racial, analfabetismo e ignorância - constituem um amálgama pelo qual o intelectual compreende "as massas" trabalhadoras. Estava aí a insolúvel contradição das lideranças operárias apontada por Castoriadis (1985): esperava-se que a classe trabalhadora cumprisse sua missão revolucionária, porém desconfiava-se de sua capacidade para tanto devido ao seu analfabetismo, sua ignorância e, para alguns 
analistas, também à sua composição étnico-racial. As lideranças e seus órgãos atribuíam a si mesmos um "árduo trabalho" e uma "difícil missão": educar a classe que deveria fazer a revolução.

Pondo em questão os discursos citados, buscamos, nos estatutos das organizações de trabalhadores, dados que possibilitassem nos aproximarmos de sua educação, não como iluminação de consciências, mas como parte significativa de seu processo de formação. Encontramos nessa fonte potencialidades e limites. 0 formato dos estatutos é padronizado pela já citada lei, que lhes garantiria aprovação e a existência regular da entidade com direitos de pessoa jurídica. Isso faz deles um discurso relativamente repetitivo e árido. No caso das associações de resistência, é notória a influência dos Congressos Operários (1906, 1913 e 1918) em seus estatutos. Ao lermos os documentos das Ligas e Uniões, constatamos a existência de termos ou mesmo trechos inteiros que se repetem.

0 tema sete do Segundo Congresso Operário (1913) tratava da "necessidade ou desnecessidade dos estatutos ou regulamentos para sindicatos" (HALL; PINHEIR0, 1979, p. 190) e, caso fossem necessários, se deveriam ou não ser uniformes. Os operários então reunidos consideraram que, tendo em vista a maior liberdade de ação possível para conseguir seus fins, os estatutos deveriam oferecer bases livres de acordo. Assim aconselhavam às sociedades de resistência abolir "regulamentos calcados em fórmulas burocráticas e coercitivas e restringi-los a simples normas administrativas despidas de qualquer determinação que fira a autonomia individual dos associados ou que conceda atribuições de mando a qualquer deles" (HALL; PINHEIRO, 1979, p. 190). De fato, os estatutos das Ligas e Uniões afınados às resoluções congressuais são mais enxutos, mais breves, vedam posições de mando a um ou outro sócio ou categorias de sócios, porém não se pode dizer que se restrinjam a simples normas administrativas. Pelo contrário, como os demais regulamentos estudados, estão repletos de afırmações de princípios e valores e, exatamente por isso, é possível detectar as particularidades de cada organização em seus textos. Ao ler suas regularidades, mas também suas peculiaridades e desvios, pretendemos dar a ver a maneira como diferentes categorias de trabalhadores inscreviam a educação em sua arquitetura associativa. Buscamos, além disso, apresentar as formas desses trabalhadores se educarem por meio da própria cultura associativa e, nesse sentido, os estatutos das associações são também para nós objetos de estudo, quando os entendemos em sua materialidade histórica, como prescrições que poderiam gerar práticas efetivas.

\section{A presença da educação na arquitetura jurídica e organizativa das entidades da classe trabalhadora}

As palavras de John Thelwall, líder radical britânico, na passagem do século XVIII para o século XIX, nos ajudam a dimensionar os vínculos entre associativismo e educação da classe trabalhadora: "0 que quer que leve os homens a se unirem, embora isso possa gerar alguns vícios, é favorável à difusão do conhecimento e, em última instância, promove a liberdade humana” (THOMPSON, 2004, p. 204). As associações mutualistas e as de resistência não se organizaram com o objetivo específico de promover educação. A finalidade principal das primeiras era auxiliar os sócios contribuintes quando se 
encontrassem sem condições de trabalho (com remédio, atendimento médico, pequenas quantias mensais, advogado etc.). As segundas surgiram para intermediar as relações entre trabalhadores e patrões, buscando conquistar direitos e a própria emancipação dos trabalhadores. Entretanto, ambas consideravam a educação como importante ferramenta para a conquista de seus objetivos; fosse ela proporcionada como benefício individual aos sócios, no caso das mutuais; fosse uma que encarnasse os interesses da classe, característica das associações de resistência.

A leitura sistemática dos estatutos das já referidas associações nos permitiu delimitar quatro eixos de análise para um panorama sobre a condição da educação na arquitetura jurídica e organizativa das entidades obreiras. São eles: a relevância atribuída, as finalidades, as ações formais e a educação pela cultura associativa. Nosso principal argumento começa pela defesa e demonstração da relevância que os trabalhadores conferiam à educação, expressa pelo lugar das diferentes ações educativas em suas associações. Apesar de a jovem república ter a educação como sua principal bandeira, meio para formação do cidadão e fundamento das próprias bases do regime, tal discurso não se reverteu na promoção do direito (SOUZA, 1998; VIDAL; SÁ; SILVA, 2013). A própria ideia de direitos sociais, tais como a previdência e os direitos trabalhistas, não existia no momento. A luta de classes terá papel fundamental em sua construção. As associações mutualistas, suas demandas e práticas terão influência sobre a constituição da previdência (DE LUCA, 1990); o movimento operário, com suas pautas de reivindicação e lutas ferrenhas contra a exploração pelo empresariado e a repressão policial, será artífice do que se consolidou nas leis trabalhistas (GOMES, 2005). A educação, condição para as lutas anteriormente afırmadas e objetivo em si das mesmas, trilha longo caminho até se consolidar como direito social; ${ }^{3}$ nesse processo, vemos seu desenvolvimento relativamente autônomo pela classe trabalhadora.

\section{Relevância, finalidades e ações educativas nas associações obreiras}

A grande maioria das entidades pesquisadas, tanto mutualistas quanto de resistência, pretendiam manter ao menos uma biblioteca e sala de leitura para uso dos sócios. Nelas deveria haver livros instrutivos, especialmente no caso das mutualistas, voltados para os ofícios dos sócios, jornais, revistas, mapas etc. Contavam com doações e era comum a designação de um sócio para o papel de bibliotecário, que cuidaria do acervo, dos utensílios, da regularidade e controle dos empréstimos. Havia, porém, entre as associações de auxílio mútuo, aquelas que destacavam a educação desde seus fins. Nesses casos, observa-se que a própria entidade chama para si a responsabilidade quanto à definição de que tipo de educação desenvolveria, criando regulamentos para suas aulas, formas de controle do trabalho docente, enfim, colocando-se ativamente sem delegar a prerrogativa pedagógica diretamente a especialistas.

Tomemos o Centro dos Empregados do Comércio e Indústria (CECI), que pretendia:

3- Apenas em 1988 a educação fundamental será considerada direito subjetivo do cidadão. (BAHIA HORTA, 2013). 
Criar cursos gratuitos de escrituração mercantil, contabilidade, taquigrafia, datilografia, português, inglês, francês e outras matérias que sejam úteis à vida comercial e industrial; fundar e manter gratuitamente, logo que a sociedade conte com dois mil sócios, um curso primário diurno para os filhos e irmãos menores dos associados; [...] A parte instrutiva tem por fim: criar cursos regulares; organizar uma biblioteca escolhida em todos os ramos dos conhecimentos úteis e uma sala de leitura; realizar conferências sobre assuntos literários, científicos e comerciais, para as quais serão convidadas pessoas de reconhecida competência; criar um jornal para defesa dos interesses das classes. [...] A parte recreativa tem por fim: promover reuniões familiares, concertos musicais, festas esportivas e outros divertimentos, a critério da diretoria. (CECI, 1920, p. 2).

Para tanto, deveria ser constituída uma Comissão de Instrução, a quem competia: “a) propor a nomeação de professores; b) organizar o programa de ensino e o regulamento interno das aulas, de comum acordo com os professores” (CECI, 1920, p. 10). Já o Grêmio dos Alfaiates (GA) punha a instrução e o recreio ao lado dos principais interesses da classe, entre os quais figuravam a regulação do mercado de trabalho e o "apoio material e moral" sem a "quebra de dignidade individual e coletiva" (GA, 1904, p. 1). A instrução era voltada para a prática profissional e deveria obedecer ao regulamento interno produzido pelos alfaiates do Grêmio. Para além do ensino técnico, deveria haver o ensino de línguas e o lazer lícito, como a "leitura, jogos lícitos e festas de caráter puramente familiar". Seu segundo artigo determina:

A associação tem como principais objetivos: $1^{\circ}$ o ensino da parte teórica da profissão de alfaiate aos filhos menores dos associados que queiram dedicar-se a essa profissão e isso por meio de aulas mantidas a expensas dos cofres associativos e sob regulamento que para tal fim, em especial, será formulado; $2^{\circ}$ a lecionação do ensino das línguas portuguesa, francesa, desenho e música gratuitamente ministrada aos sócios e seus filhos menores nas aulas que para esse fim e também na sede social deverão ser instituídas e regulamentadas. (GA, 1904, p. 1).

No universo das associações de resistência, não era menor a relevância atribuída à educação, embora ela aí assumisse diferentes finalidades. Havia um lugar relativamente marcado, consoante com as deliberações dos Congressos Operários de 1906, 1913 e 1918 sobre educação. Vemos as formulações mais frequentes como expressas, por exemplo, nos estatutos da Associação dos Operários em Fábricas de Tecido da Mooca, que tinha entre seus fins "Promover a instrução e educação moral dos associados" (AOFTM, 1918, p. 1). Ou ainda do Centro Operário de São Bernardo, que pretendia "elevar o nível moral e intelectual dos trabalhadores" (COSB, 1919, p. 1). Os meios utilizados seriam, em geral, as escolas, bibliotecas, palestras e conferências, às vezes acrescidas por panfletos, excursões, apresentações teatrais e, frequentemente, a criação de um jornal da classe. Cabe apontar, no entanto, que jornais e panfletos tinham finalidade expressa de propaganda. Consideramos a impossibilidade de separação entre a educação dos trabalhadores e propaganda do movimento operário; por isso encaramos jornais e panfletos como meios educativos, o que não significa que os sujeitos por nós estudados os vissem dessa maneira. É possível imaginar, ainda, a própria sede da associação como espaço instrutivo, onde os trabalhadores 
se educavam de forma relativamente autônoma. A Sociedade União Beneficente dos Ensacadores de Café e Cereais incluía entre os direitos dos sócios "frequentar a sede para leitura dos jornais e palestras nos dias determinados pelo regulamento interno da sociedade" (SUBECC, 1912, p. 3).

Percebemos, portanto, uma perspectiva ampla de educação dinamizada pelos trabalhadores que vai além do formato escolar. A Liga dos Trabalhadores da Light, por exemplo, situa a educação no conjunto da cultura da classe. As escolas são as últimas formas de educação citadas e qualificadas. No terceiro tópico de seus fins, a Liga se propõe a "esforçar-se pela cultura dos trabalhadores criando bibliotecas, promovendo conferências, palestras e excursões; difundindo seus jornais de propaganda reivindicadora, editando livros, folhetos e avulsos, criando e patrocinando as escolas baseadas no método racionalista e científico" (LTL, 1919, p. 1). A cultura dos trabalhadores e sua educação seriam um dos pontos de um vasto programa que nos permitiremos citar extensivamente, pois possibilita ao(à) leitor(a) acercar-se da materialidade das condições de vida e luta daqueles sujeitos:

A L. T. L. tendo por objetivo máximo a completa emancipação do proletariado desenvolverá sua ação imediata no sentido de: a) zelar pelos direitos de associação, de reunião e de livre propaganda - dos princípios da emancipação social; b) promover a defesa dos trabalhadores e propagandistas em caso de prisão, perseguição, abuso, injustiça de que sejam vítimas [...]; c) esforçar-se pela cultura dos trabalhadores criando bibliotecas, promovendo conferências, palestras e excursões; difundindo seus jornais de propaganda reivindicadora, editando livros, folhetos e avulsos e criando e patrocinando as escolas baseadas no método racionalista e cientifico; d) mover ativa campanha contra o alcoolismo, que é um dos vícios mais arraigados no seio da classe trabalhadora e que tem sido um obstáculo para sua organização e luta contra os exploradores [...]; e) participar de toda ação proletária contra [...] criminosos manejos comerciais que fazem elevar os preços dos gêneros alimentícios [...]; f) agir com todos os trabalhadores contra os aumentos de impostos de toda sorte que contribuem para tornar mais penosas as condições do povo; g) prestar o seu concurso às campanhas obreiras tendentes a conseguir o barateamento dos aluguéis de casas, bem como para que ofereçam conforto e higiene; h) fazer com que os trabalhadores não sejam forçados a executar serviços excessivos e brutais, expondo-se a inclemências do tempo, e que os lugares de trabalho ofereçam todas as condições necessárias de segurança, de higiene e de comodidade para evitar os acidentes e as moléstias hoje tão habituais [...]; i) exigir da parte de todos os encarregados de serviço de todas categorias a mais completa urbanidade e absoluto respeito para com os trabalhadores; j) impedir que sejam ocupados no trabalho menores de 14 anos ou de físico deficiente; k) conseguir que os operários, em caso de desastre, sejam indenizados [...]; 1) firmar de maneira geral a jornada de 8 horas [...]; p) fazer com que o trabalho noturno só seja admitido nos casos de benefício público, ou de imprescindível necessidade, devendo, entretanto, em tais casos, serem executados em condições de permitirem o repouso devido aos operários [...]; q) conseguir aumento de salário na proporção do custo da vida [...]; s) conseguir a abolição de todas as multas, descontos e mensalidades para caixas de associações organizadas no seio da companhia por seus diretores; t) fazer com que todos os trabalhadores tenham indistintamente um dia de descanso na semana e gozem de uma féria anual com todos os vencimentos". (LTL, 1919, p. 1-3, grifos da autora). 
Trata-se de um processo em que a classe trabalhadora se educa no momento mesmo de constituir-se como classe e, em sua formação, educa a própria sociedade por meio de conflitos e negociações travadas com patrões, com o Estado e com outros grupos sociais. Podemos perceber tal papel educativo da classe operária "para fora" ao tomarmos as exigências aos patões, mestres e gerentes para que mantivessem "a mais completa urbanidade e absoluto respeito com os trabalhadores" (LTL, 1919, p. 2). Aqui a urbanidade não era prerrogativa das elites a ser incutida nos operários. Realiza-se a inversão do discurso dominante, para o qual seriam os operários a classe rústica, desordeira, a quem deveria ser ensinada a civilidade e a boa conduta.

Em síntese, se, para as mutuais, a educação tinha por finalidade precípua qualificar o trabalho dos sócios, formar seus filhos para o trabalho, oferecendo-lhes um serviço que o Estado não se mostrava capaz de prover, para as associações de resistência, a educação deveria concorrer para a emancipação do proletariado, por meio de projetos pedagógicos próprios e confrontantes à ordem vigente. Alinhados às ideologias do movimento operário internacional, tendo por pressuposto que a libertação dos trabalhadores seria obra dos próprios trabalhadores, a União dos Chapeleiros estabelecia, como objetivo da instrução dos operários, " "habilitá-los para resolver por si mesmos a questão social” (UC, 1917, p. 2). Por seu turno, a União dos Trabalhadores Gráficos também expressa o papel da educação na consecução dos objetivos de emancipação pela luta de classes:

A U.T.G. tendo por objetivo promover o melhoramento econômico, intelectual e moral da classe, capacitando-a para realização de uma luta inteligente e ampla em favor de sua emancipação integral aceita, como princípio basilar da sua existência, a luta de classes e declara que intervirá nela utilizando os meios de ação próprios e especiais da organização operária. (UTG, 1919, p. 1).

Para tanto, os gráficos fariam uso da educação racionalista e da instrução profissional.

\section{Educação pela cultura associativa}

Além das ações educativas claramente delineadas e dirigidas, abordadas na seção anterior, os estatutos nos dão a ver formas mais difusas, porém mais abrangentes de aprendizado. Delimitamos, neste momento, três características marcantes do que estamos chamando educação pela cultura associativa: 1) ensejo ao envolvimento dos trabalhadores com o universo letrado; 2) normalização do comportamento moral, civil e associativo; 3) aprendizado das regras da vida política e dos direitos.

Comecemos pelo fato de que as bases de acordo da vida associativa se apresentavam como peças escritas. Junte-se a isso, no caso das mutuais, porém não das associações de resistência, a própria proposta de incorporação do novo sócio, que devia ser feita por escrito apresentando: nome, estado, profissão, idade, nacionalidade, endereço do proposto. Constatamos que a maior parte das associações mutualistas estudadas cobravam, no

4- A União dos Chapeleiros tinha em seu programa o estreitamento de laços entre os chapeleiros e os trabalhadores de todo o mundo. Era aderente à Federação Internacional dos Operários Chapeleiros e à Confederação Operária Brasileira. 
momento do ingresso do sócio, uma taxa de $1 \$ 000$ (mil réis) pelos estatutos, o que nos leva a pensar que o sócio tinha em suas mãos um exemplar da lei social. Algumas associações também distribuíam seus relatórios e balanços financeiros ao conjunto dos associados. Da mesma forma, algumas associações de resistência tornavam públicos seus relatórios pela imprensa operária. Sobre esse material deviam ser realizadas práticas de leitura coletiva que informariam tomadas de decisões. A leitura em voz alta, durante a assembleia, daria aos sócios analfabetos o acesso às informações contidas no texto escrito. É o caso da Associação Auxiliadora dos Carpinteiros e Pedreiros, que determina como deveres da diretoria "mandar imprimir anualmente o balancete da receita e da despesa e distribuí-lo aos sócios, acompanhado do respectivo relatório que deve ser lido em Assembleia Geral e submetido à sua aprovação, dando sobre as contas todos os esclarecimentos exigidos" (AACPMC, 1903, p. 1119).

Entre as principais preocupações educativas das entidades estudadas estava o condicionamento do comportamento moral, civil e associativo, variando os valores que pautavam tais comportamentos. A boa conduta moral era condição para admissão às associações mutualistas. Da mesma forma, eram punidos aqueles que

Promovessem desordem ou desacato aos funcionários da associação no exercício de seus cargos, [ou] [...] o que por seu comportamento irregular possa comprometer o crédito da associação, escrevendo nos jornais contra membros da diretoria, sem primeiro recorrer à Assembleia Geral. (AACPMC, 1903, p. 1119).

Cabe notar que as exigências de conduta moral implicavam o acesso aos benefícios, como pensões às viúvas. As mulheres eram particularmente vigiadas sob os parâmetros da "honestidade", aparentemente vinculada à moral sexual dominante. No caso da Associação Beneficente Operária $1^{\circ}$ de Maio de Vila Galvão, eram restringidos os direitos a auxílios médicos e pecuniários quando os sócios estivessem acometidos de doenças "venéreas, ou causadas por embriaguez". É possível observar, nessa documentação, estratégias de controle aos impulsos, aos conflitos e mesmo de controle ideológico.

Ao lado das citadas regras da vida civil, que podiam internamente reforçar ou relativizar as leis e valores sociais vigentes, estavam regras da vida política. Defendemos que os meios associativos possibilitaram relevante aprendizado do exercício da política, do debate público, além dos valores e técnicas de organização e participação nas causas de interesse coletivo. Estes, não sendo dados naturais, precisavam ser pensados, previstos, instituídos e aprendidos. É o que revelam as constantes determinações de que os sócios deveriam exercer com zelo os cargos para que fossem eleitos, comparecer às assembleias, com esclarecimento de que o não comparecimento implicava a delegação de seu voto aos sócios presentes, não podendo reclamar quanto às deliberações tomadas. As próprias técnicas, hoje consideradas básicas por nós, para a realização do debate público precisavam ser explicitadas e começavam a ser interiorizadas. Em muitas mutuais, como a Associação Auxiliadora dos Carpinteiros, Pedreiros e Mais Classes, o presidente tinha um papel importante nesse processo. Cabia a ele dirigir as discussões, devendo "Chamar à 
ordem os que dela se afastarem e impedir que o sócio orador seja interrompido e que este empregue palavras ou gestos inconvenientes" (AACPMC, 1903, p. 5). E, ainda,

Nenhum sócio poderá falar sem ter pedido a palavra ao presidente e esse concedido. 0 sócio orador tem o direito de ser escutado com atenção e ninguém poderá alterar a ordem e sossego com manifestações desordenadas, competindo ao presidente exclusivamente o direito de admoestar, ou retirar a palavra do sócio quando este esteja fora da ordem. (AACPMC, 1903, p. 5).

No mesmo espírito, são expostas as regras e técnicas básicas dos processos eleitorais. Os estatutos da União dos Chapeleiros explicam que "As votações serão feitas por levantada de braço, em pé, sentados, nominais ou por escrutínio secreto. A minoria deverá conformar-se em atender as deliberações da maioria” (UC, 1917, p. 14).

Nas associações de resistência, o aprendizado de direitos fez-se de forma mais extensa e intensa, especialmente no que diz respeito aos direitos da classe trabalhadora, sendo o próprio termo direito mais constante em seus estatutos. Apareciam nos fins da Associação dos Operários em Fábricas de Tecido da Mooca "intervir, como legítimo órgão dos associados, em todas as questões que se suscitem entre esses e os patrões, defendendo e zelando pelos direitos e interesses dos primeiros" (AOFTM, 1918, p. 1, grifos da autora).

No tocante aos direitos internos das entidades, observa-se uma ampliação da tendência democrática nas sociedades de resistência quando comparadas às mutuais. Nas primeiras, eram raras as restrições ao voto; nas segundas, frequentemente impediamse mulheres e analfabetos. A participação política, principalmente nas associações de resistência, ocupava um lugar duplo - um direito dos indivíduos e um dever para com a classe. É paradigmático o caso da Liga Operária do Ypiranga, associação que congregava principalmente os trabalhadores das fábricas de tecidos do bairro, cujos sócios que não comparecessem às assembleias podiam ser multados. Eram seus deveres:

Ser solidários moral e materialmente em todas as questões de interesse comum pleiteadas oficialmente pela Liga, observar rigorosamente as disposições desses estatutos e suas futuras modificações regularmente introduzidas e comparecer nas assembleias sob pena de multa... (LOY, 1919, p. 2).

A mesma Liga nos surpreende ao tratar a decisão dos indivíduos de se alfabetizarem como problema coletivo ao determinar que "Todo sócio tem o dever de aprender a ler e escrever" (LOY, 1919, p. 2). Entretanto, ao contrário de uma série de associações, a Liga Operária do Ypiranga não excluía o analfabeto do direito de votar e ser votado. É interessante notar, ainda, como seus estatutos enfatizam mais de uma vez que ambos os sexos gozam de direitos e deveres absolutamente iguais.

\section{Considerações finais}

Esta investigação busca compreender como os trabalhadores fizeram sua educação e se fizeram por meio dela. $\mathrm{Ou}$, ainda, a participação da educação na formação da classe 
trabalhadora e a importância histórica da atuação da classe trabalhadora na constituição do direito à educação.

Ao nos debruçarmos sobre os estatutos das associações de auxílio mútuo e de resistência promovidas por trabalhadores, encontramos dados alternativos e complementares à imprensa operária, fonte majoritariamente utilizada na produção da história da classe trabalhadora. A leitura de suas regularidades, mas também de suas peculiaridades e desvios nos possibilitou observar a maneira como diferentes categorias de trabalhadores inscreviam a educação em sua arquitetura associativa. Além disso, encontramos aí a própria cultura associativa como meio pelo qual os trabalhadores se educavam.

É importante demarcar que, para as associações mutualistas, a educação tinha por finalidade precípua qualificar o trabalho dos sócios, formar seus filhos para o trabalho, oferecendo-lhes um serviço que o Estado não se mostrava capaz de prover, enquanto que, para as associações de resistência, a educação deveria concorrer para a emancipação do proletariado, por meio de projetos pedagógicos próprios e confrontantes à ordem vigente.

Guardadas essas significativas diferenças, defendemos que, de modo geral, o aprendizado de direitos, da participação política, de valores morais e do valor da leitura, escrita e mais conhecimentos formais até aqui demonstrados ocorriam entre os trabalhadores indissociáveis da própria luta por sobrevivência e emancipação. A Liga dos Trabalhadores da Light expressou a dinâmica dessa educação mútua relativamente autônoma:

\footnotetext{
A L.T.L servir-se-á unicamente para o trabalho de propaganda e educação dos trabalhadores e sua luta contra a desigualdade econômico-social da ação consciente e solidária de seus associados e dos meios próprios da ação direta, variáveis segundo as circunstâncias de lugar e do momento. (LTL, 1919, p. 3).
}

No momento em que vivemos perdas de direitos históricos como a previdência, a legislação trabalhista e a própria educação pública, em função do aprofundamento das reformas neoliberais do Estado brasileiro, tematizar as práticas associativas por meio das quais trabalhadores e trabalhadoras, há cem anos, educaram-se, formaram-se e, nesse processo, foram partícipes centrais na invenção desses mesmos direitos para os quais procuraram educar a sociedade, pode nos apontar caminhos para refletir sobre os desafios do presente.

\section{Referências}

AACPMC. Associação Auxiliadora dos Carpinteiros, Pedreiros e Mais Classes. Estatutos, 1903.

ABOPMVG. Associação Beneficente Operária $1^{0}$ de Maio Vila Galvão. Estatutos, 1917. p. 8.

AMCSP. Associação Mútua dos Carteiros de São Paulo. Estatutos, 1920, p. 2.

AOFTM. Associação dos Operários em Fábrica de Tecidos da Mooca. Estatutos, 1918. 
BAHIA HORTA, José Silvério. Direito à educação, obrigatoriedade escolar e extensão da escolaridade. In: VIDAL, Diana Gonçalves; SÁ, Elisabeth Figueiredo de; SILVA, Vera Lúcia Gaspar da (Org.). Obrigatoriedade escolar no Brasil. Cuiabá: EdUFMT, 2013. p. 381-398.

BATALHA, Cláudio H. M. Sociedades operárias e mutualismo. Cadernos AEL, Campinas, v. 6, n. 10/11, 1999. CASTORIADIS, Cornelius. A experiência do movimento operário. São Paulo: Brasiliense, 1985.

CECl. Centro dos Empregados no Comércio e na Indústria. Estatutos, 1920.

COSB. Centro Operário de São Bernardo. Estatutos, 1919.

DE LUCA, Tânia R. 0 sonho do futuro assegurado: 0 mutualismo em São Paulo. São Paulo: Contexto; Brasília, DF: CNPq, 1990. (República).

HARDMAN, Francisco Foot. Nem pátria, nem patrão! Vida operária e cultura anarquista no Brasil. São Paulo: Brasiliense, 1984.

GOMES, Ângela de Castro. A invenção do trabalhismo. 3. ed. Rio de Janeiro: FGV, 2005.

GA. Grêmio dos Alfaiates. Estatutos, 1904, p. 1.

HALL, Michael M.; PINHEIRO, Paulo Sérgio. A classe operária no Brasil (1889-1930): condições de vida e de trabalho, relações com os empresários e o Estado. São Paulo: Editora Alfa e Ômega, 1981. (Documentos; v. 2).

HALL, Michael M.; PINHEIRO, Paulo Sérgio. A classe operária no Brasil (1889-1930): 0 movimento operário. São Paulo: Alfa e Ômega, 1979. (Documentos; v. 1).

LOY. Liga Operária do Ypiranga, Estatutos, 1919.

LTL. Liga dos Trabalhadores da Light. Estatutos, 1919.

MAC CORD, Marcelo; BATALHA, Claudio H. M. Organizar e proteger: trabalhadores, associações e mutualismo no Brasil (séculos XIX e XX). Campinas: Unicamp, 2014.

MAC CORD, Marcelo; MACIEL, Osvaldo (Org.). Os trabalhadores e o mutualismo. Mundos do Trabalho, v. 2, n. 4, 2010. Publicação eletrônica semestral do GT "Mundos do Trabalho"- ANPUH.

PEREIRA, Astrogildo. Nada de Precipitação. A Plebe, n. 120, 4 jun. 1921.

SANTOS, Carlos José Ferreira. Nem tudo era italiano: São Paulo e pobreza (1890-1915). 3. ed. São Paulo: Anablume:Fapesp, 2008.

SUBECC. Sociedade União Beneficente dos Ensacadores de Café e Cereais. Estatutos, 1912. 
SOUZA, Rosa Fátima. 0 direito à educação. Campinas: Unicamp, 1998.

THOMPSON, Edward Palmer. A formação da classe operária inglesa: a árvore da liberdade. Tradução de Denise Bottmann. v. 1. Rio de Janeiro: Paz e Terra, 2004.

UC. União dos Chapeleiros. Estatutos, 1917.

UTG. União dos Trabalhadores Gráficos. Estatutos, 1919.

VIDAL, Diana Gonçalves; SÁ, Elisabeth Figueiredo de; SILVA, Vera Lúcia Gaspar da (Org.). Obrigatoriedade escolar no Brasil. Cuiabá: EdUFMT, 2013.

Recebido em: 15.05.2017

Revisões em: 04.07.2017

Aprovado em: 08.08.2017

Ana Luiza Jesus da Costa é doutora em educação pela Universidade de São Paulo, professora no Departamento de Filosofia e Ciências da Educação da Faculdade de Educação da Universidade de São Paulo. Atua na área de História da Educação. 